\title{
APLIKASI METODE AKTIVASI FISIKA DAN AKTIVASI KIMIA PADA PEMBUATAN ARANG AKTIF DARI TEMPURUNG KELAPA (Cocos nucifera L)
}

\author{
Farida Aryani ${ }^{1}$, Fina Mardiana ${ }^{2}$, Wartomo ${ }^{3}$ \\ ${ }^{1}$ Jurusan Teknologi Pertanian, Politeknik Pertanian Negeri Samarinda. \\ E-mail: ary ani02@yahoo.com
}

Submisi : 5 Oktober 2018, Penerimaan : 21 Februari 2019

\begin{abstract}
ABSTRAK
Kebutuhan arang aktif di Indonesia semakin meningkat, seiring dengan kemajuan teknologi dan industri di tanah air. Kebutuhan yang meningkat ini harus didukung pula oleh peneliti dan pengusaha yang berkecimpung dibidang arang aktif agar dapat memproduksi arang aktif yang bermutu baik dari segi kualitas maupun kuantitasnya. Dalam rangka mengembangkan metode pembuatan arang aktif dilaboratorium maka dilakukan penelitian pembuatan arang aktif dengan menggunakan dua metode aktivasi yaitu metode aktivaasi fisika dan metode aktivasi kimia. Tujuan dari penelitian ini adalah untuk mengetahui evektivitas dari metode aktivasi fisika dan kimia pada pembuatan arang aktif tempurung kelapa. Aktivasi fisika dilakukan dengan pembakaran pada suhu $500^{\circ} \mathrm{C}$ selama 4 jam, sedang aktivasi kimia dilakukan dengan melakukan perendaman menggunakan larutan $\mathrm{NaOH}$ 0,2 N selama 18 jam. Pengujian kualitas mengacu pada SNI 06-3730-1995 tentang syarat mutu dan pengujian arang aktif. Hasil Analisis arang aktif metode aktifasi fisika diperoleh rendemen sebesar $86.7 \%$, kadar abu 8,46\%, kadar air 6,0\%, kadar zat mudah menguap 37,12\%, dan daya serap iodium sebesar $755,32 \mathrm{mg} / \mathrm{g}$. Metode aktifasi kimia menghasilkan rendemen sebesar $63,7 \%$, kadar abu $0,75 \%$, kadar air 3,6\%, kadar zat mudah menguap 35,06\%, dan daya serap iodium sebesar $317,25 \mathrm{mg} / \mathrm{g}$.
\end{abstract}

Kata kunci : arang aktif; aktivasi fisika; aktivasi kimia; tempurung kelapa

\section{PENDAHULUAN}

Seiring pertumbuhan industri dimasyarakat kebutuhan karbon aktif di Indonesia semakin meningkat seiring Namun, peningkatan kebutuhan karbon aktif tidak diimbangi dengan adanya produsen karbon aktif di dalam negeri sehingga untuk memenuhi kebutuhan tersebut harus mengimpor.

Arang aktif banyak dimanfaatkan oleh pabrik-pabrik untuk berbagai tujuan, diantaranya dibidang kesehatan digunakan dalam penanganan keracunan eksternal dan terapi diare sekretonik (Muthscer, 1986). Dalam mengatasi masalah lingkungan kemampuan arang aktif sebagai penghilang logam tersebut dipengaruhi oleh pH dan konsentrasi karbon. Kenaikan kadar karbon menaikkan persen adsorpsi arang aktif terhadap ion logam. Penggunaan arang aktif sangat penting dalam proses penjernihan air dan udara Harris (1999). Selain mengadsorpsi logam-logam seperti besi, tembaga. nikel, juga dapat menghilangkan bau, warna dan rasa yang terdapat dalam larutan atau buangan air.

Berdasarkan latar belakang di atas, maka perlu dilakukan penelitian tentang aktivasi arang dari tempurung kelapa dengan menggunakan metode aktivasi fisika dan aktivasi kimia dengan $\mathrm{NaOH}$ sebagai aktivator sehingga diperoleh arang aktif yang berkualitas sesuai standar SNI.

Tujuan penelitian ini adalah untuk mengetahui efektivitas metode dari proses pembuatan aktif dari tempurung 
kelapa dengan metode aktivasi fisika dan metode aktivasi kimia

\section{METODE PENELITIAN}

Alat

Peralatan yang digunakan pada penelitian ini adalah f,urnace, Oven listrik, erlemeyer, gelas ukur $250 \mathrm{ml}-500$ $\mathrm{ml}$, labu ukur $10 \mathrm{ml}-100 \mathrm{ml}$, corong, spatula, neraca analitik, desikator, ayakan mesh 100.

\section{Bahan}

Bahan yang digunakan pada penelitian ini adalah : Arang tempurung kelapa, zat aktivator $\mathrm{NaOH} 0,2 \mathrm{M}$, aquadest, larutan iodium $0,1 \mathrm{~N}$, larutan natrium tiosulfat $0,1 \mathrm{~N}$, larutan amilum 1 $\%$, aluminium foil, kertas saring, tepung tapioka.

\section{Prosedur Penelitian}

\section{Persiapan bahan baku}

Bahan baku diambil dari PT. ljo Item Samarinda. Bahan baku tempurung kelapa (Cocos nucifera $L$ ) sebanyak $5 \mathrm{~kg}$ sudah menjadi arang selanjutnya di tumbuk hingga halus dan di ayak menggunakan mesh 100.

\section{Persiapan sampel}

Bahan baku berupa arang tempurung kelapa dihaluskan dengan cara ditumbuk, selanjutnya arang diayak dengan ukuran mesh 100.

\section{Metode aktivasi fisika}

Pada proses menggunakan metode aktivasi fisika arang tempurung kelapa ditimbang lalu dimasukan kedalam tanur pembakaran menggunakan tempatur $500{ }^{\circ} \mathrm{C}$ selama 4 jam, setelah itu sampel didinginkan di dalam desikator kemudian di timbang kembali untuk mendapatkan rendemen arang aktif.

Arang aktif yang telah diperoleh di uji standard mutu dengan mengacu pada Standar Nasional Indonesia (SNI) 06-3730-1995 tentang syarat mutu dan pengujian arang aktif.

\section{Metode aktivasi kimia}

Arang tempurung kelapa sebanyak 100 gram lalu direndam dengan larutan $\mathrm{NaOH} 0,2 \mathrm{~N}$ selama 18 jam kemudian disaring dengan kertas saring setelah itu dicuci dengan aquadest hingga $\mathrm{pH}$ netral. Setelah itu arang yang telah diaktivasi dikeringkan menggunakan oven pada suhu $150^{\circ} \mathrm{C}$, kemudian ditimbang untuk mendapatkan nilai rendemen. Arang aktif yang telah diperoleh di uji standard mutu dengan mengacu pada Standar Nasional Indonesia (SNI) 06-37301995 tentang syarat mutu dan pengujian arang aktif.

5. Perhitungan rendemen arang aktif :

Rendemen $=\frac{\text { Berat arang Aktif }}{\text { Berat arang }} \times 100 \%$

Uji Kadar Air Contoh uji arang sebanyak \pm 1 gram dikeringkan dalam oven pada suhu $(103 \pm 2)^{\circ} \mathrm{C}$ sampai beratnya konstan. Kemudian didinginkan dalam desikator. Kadar air arang aktif dihitung dengan rumus sebagai berikut :

$$
\begin{aligned}
& \quad \text { Kadar air }(\%)=\frac{A}{B} \times 100 \% \\
& \mathrm{~A}=\text { Berat contoh awal } \\
& \mathrm{B}=\text { Berat contoh kering tanur }
\end{aligned}
$$

6. Uji Penetapan Kadar Zat Menguap

Cawan berisi arang aktif dipanaskan pada furnace dengan suhu $950^{\circ} \mathrm{C}$ selama 6 menit. selanjutnya didinginkan dalam desikator dan ditimbang.

$$
\begin{aligned}
& \text { Kadar Zat Mudah Menguap (\%) }=\frac{A}{B} \times 100 \% \\
& \quad \mathrm{~A}=\text { Selisih berat contoh uji } \\
& \mathrm{B}=\text { Berat contoh kering }
\end{aligned}
$$




\section{Kadar Abu}

Cawan yang sudah berisi contoh dimasukkan ke dalam furnace, perlahan-lahan dipanaskan mulai dari suhu kamar sampai $800^{\circ} \mathrm{C}$ selama 2 jam. Selanjutnya didinginkan dalam desikator sampai beratnya konstan, kemudian ditimbang bobotnya.

Kadar $A b u(\%)=\frac{\text { Berat } A b u(g)}{\text { Berat Contoh mula-mula }(g)} \times 100 \%$

\section{Uji Daya Serap Terhadap lodium}

Sampel arang aktif ditimbang sebanyak 0,5 gram dan dicampurkan dengan larutan lodium 0,1 N sebanyak $50 \mathrm{ml}$ kemudian dikocok dengan alat pengocok selama 15 menit, kemudian dipindahkan kedalam tabung sentrifugal sampai arang aktif turun, setelah itu diambil $10 \mathrm{ml}$ larutan dan tambahkan aquades 30 kemudian dititrasi dengan natrium tiosulfat $0,1 \mathrm{~N}$,jika warna kuning pada larutan samar, ditambahkan larutan amilum $1 \%$ ke dalam larutan tersebut sebagai indikator. Dititrasi kembali warna biru tua hingga warna bening.

\section{HASIL DAN PEMBAHASAN}

Tabel 1. hasil aktivasi arang aktif

\begin{tabular}{cccc}
\hline No & $\begin{array}{c}\text { Sifat fisika dan kimia } \\
\text { arang aktif }\end{array}$ & \multicolumn{2}{c}{ Aktivasi arang tempurung } \\
\cline { 3 - 4 } & Rendemen & $63,7 \%$ & $86,7 \%$ \\
\hline 1 & Kadar air & $3,6 \%$ & $6,0 \%$ \\
\hline 2 & Kadar abu & $0,50 \%$ & $4,27 \%$ \\
\hline 3 & Zat mudah menguap & $40,52 \%$ & $37,03 \%$ \\
\hline 4 & Penyerapan yodium & $317,25 \%$ & $355,32 \%$ \\
\hline 5 & & &
\end{tabular}

Dari Tabel dapat dilihat bahwa hasil arang aktif dengan metode aktivasi fisika memiliki rendemen sebesar 86,7 $\%$ sedangkan rendemen untuk aktivasi yang menggunakan $\mathrm{NaOH}$ sebagai aktivator memiliki rendemen sebesar $63,7 \%$. Kedua metode ini menghasilakan rendemen yang berbeda yang mana metode aktivasi kimia dengan larutan $\mathrm{NaOH} \quad 0,2 \mathrm{~N}$ lebih rendah dibanding dengan metode aktivasi menggunakan tempratur. Penyebab rendahnya rendemen pada proses aktivasi menggunakan $\mathrm{NaOH}$ ialah karena pada proses ini pencucian dan penyaringan arang yang dilakukan berulang kali membuat ada sebagian arang aktif yang terlarut atau terbuang selama proses ini. Sedangkan pada proses aktivasi menggunakan temperatur, arang aktif dipanaskan dengan temperature tinggi sehingga akan menguapkan zat-zat yang mudah menguap (volatile matter) tanpa banyak kehilangan unsur karbonnya.

Dan dapat dilihat bahwa hasil arang aktif dari perendaman dengan larutan kimia memiliki kadar air sebesar $3,6 \%$, sedangkan pada aktivasi dengan fisika memliliki kadar lebih tinggi yaitu sebesar 6,0. Kadar air yang rendah pada aktivasi kimia karena pada proses pencucian ukuran partikelnya menjadi lebih kecil. Hal ini yang menyebabkan kadar air lebih kecil yang mana pendapat ini diperkuat oleh (Ramdja, dkk, 2008) yang mana dikatakan bahwa semakin kecil ukuran partikel maka kadar air arang aktif semakin menurun.

Namun demikian kedua metode ini menghasilkan kadar air yang sesuai standar yang dipersyaratkan oleh SNI 06-3730-1995.

Kadar abu pada aktivasi kimia miliki kadar yang lebih rendah yaitu sebesar $0.75 \%$ sedangkan akivasi fisika memiliki kadar abu yang lebih tinggi sebesar $4,27 \%$. Proses pencucian pada aktivasi kimia dapat melarutkan logamlogam atau mineral yang ada pada arang aktif sehingga kadar abunya menjadi relativ lebih rendah dibanding aktivasi secara fisika. Metode aktivasi fisika dimana arang dipanaskan dengan suhu $500^{\circ} \mathrm{C}$, mineral yang yang ada tetap terkandung didalam arang dan tidak dapat menguap sehingga kadar abu dari arang aktif yang dihasilkan menjadi lebih tinggi. Dari kedua metode 
ini aktivasi secara kimia masuk dalam standar yang dipersyaratkan oleh SNI 06-3730-1995 yaitu sebesar maksimal $2,5 \%$.

Sedangkan untuk pengujian zat mudah menguap pada metode aktivasi fisika memiliki nilai sebesar $37,03 \%$ dan pada aktivasi menghasilkan nilai sebesar $40,52 \%$. Pada proses aktivasi kimia dilakukan proses perendaman menggunakan bahan aktivator. Bahan ini akan masuk diantara sela-sela lapisan hexagonal dan selanjutnya membuka permukaan yang tertutup (Lempang, 2014). Pada proses ini bahan aktivator juga melarutkan zat-zat yang masih terdapat di dalam arang seperti hidrokarbon, abu, nitrogen, dan sulfur. Pada proses aktivasi secara fisika arang dipanaskan pada suhu $500^{\circ} \mathrm{C}$ sehingga pori-pori akan terbuka dengan adanya penetrasi panas. Tetapi dengan pemanasan pada suhu $500^{\circ} \mathrm{C}$ zat mudah menguap yang dihasilkan masih tinggi karena menurut (Polii, 2017) pada suhu ini masih terbilang rendah karena belum mampu mengurai atau menguapkan senyawa-senyawa kompleks yang terdapat dalam arang seperti senyawa belerang, nitrogen, dan senyawa lainnya. Pernyataan ini juga diperkuat oleh Pari 2006, pada pemanasan $700^{\circ} \mathrm{C}$ senyawa sulfur dan nitrogen dalam arang tidak dapat menguap.

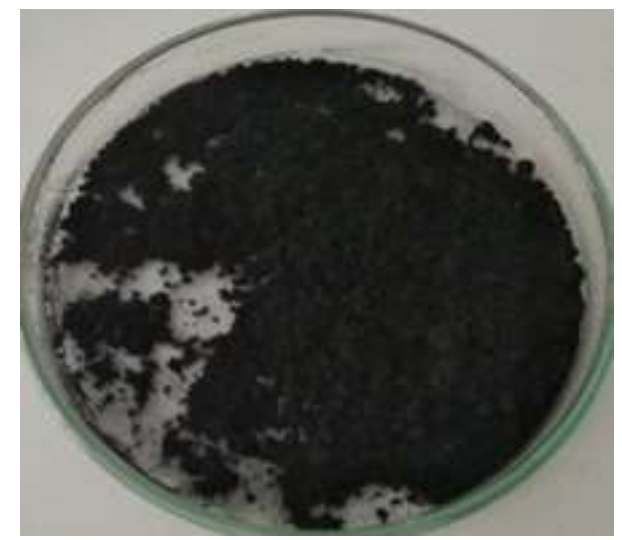

Gambar 1. Arang aktif
Pada pengujian penyerapan iodium menghasilkan nilai sebesar $317,25 \mathrm{mg} / \mathrm{gr}$ pada metode aktivasi kimia dan pada metode aktivasi fisika sebesar 555,32 mg/gr. Metode aktivasi fisika mempunyai nilai lebih tinggi dibanding aktivasi kimia, namun demikian nilainya belum sesuai dengan standard yang dipersyaratkan oleh $\mathrm{SNI}$ 06-3730-1995 yaitu min $750 \mathrm{mg} / \mathrm{gr}$. Rendahnya nilai yang diperoleh pada aktivasi kimia diduga karena masih adanya zat aktivaror yang belum tercuci sempurna sehingga menutupi pori-pori dari arang aktif.

\section{KESIMPULAN DAN SARAN}

Dari hasil penelitian yang dilakukan dapat disimpulkan bahwa arang aktif yang menggunakan metode aktivasi fisika mempunyai rendemen, kadar air dan kadar abu yang lebih tinggi dibanding akvtiasi kimia, namun memiliki kadar zat mudah menguap yang lebih rendah dibanding aktivasi kimia. Untuk penyerapan iodium metode aktivasi fisika menggunakan temperatur tinngi memiliki daya serap lebih tinggi dibanding aktivasi menggunakan bahan kimia.

Untuk memperoleh hasil maksimal dalam pembuatan arang aktif dengan menggunakan metode aktivasi fisika sebaiknya menggunakan suhu aktivasi yang lebih tinggi agar kualitas arang aktif yang dihasilkan lebih baik lagi.

\section{DAFTAR PUSTAKA}

1995. "SNI 06-3730-1995: Arang Aktif Teknis". Dewan Standarisasi Nasional. Jakarta.

Harris, P. 1999. On charcoal. Interdiciplinary science review 24(4): 301-306

Lempang, M. Info Teknis Eboni. Vol 11 No 2, Desember 2014 : 65-80 
Muthscer, E. 1986. Dinamika obat. ITB

Bandung, Edisi kelima.

Terjemahan Mathilda BW, Anna

SR. Penerbit ITB Bandung : 729-

731

Pari G, Hendra D, Pasaribu RA, 2006.

Pengaruh Lama Waktu Aktivasi

dan Konsentrasi Asam Fosfat Terhadap Mutu Arang Aktif kayu

Accacia mangium. Jurnal

Penelitian Hasil Hutan 24(1) : 33-

46

Polii FF. 2017. Jurnal Industri Hasil

Perkebunan Vol 12 No 2

Desember : 21-2 